\title{
Study on Binding Affinity of a Glutathione $S$-Transferase (GST) Fusion Protein to DNA Probe
}

\author{
Faiza Ahmed Ali', Nada Babiker Hamza ${ }^{2 *}$ \\ ${ }^{1}$ Department of Biology, College of Applied \& Industrial Sciences, University of Juba, Juba, South Sudan. \\ ${ }^{2}$ Commission for Biotechnology and Genetic Engineering, National Center for Research, Khartoum, Sudan \\ Email: ${ }^{*}$ nada.hamza@gmail.com
}

Received 15 April 2015; accepted 10 May 2015; published 12 May 2015

Copyright (C) 2015 by authors and Scientific Research Publishing Inc.

This work is licensed under the Creative Commons Attribution International License (CC BY). http://creativecommons.org/licenses/by/4.0/ C) (i) Open Access

\section{Abstract}

The aims of this work were to: i) purify GST-fusion protein from bacterial cell extracts of Escherichia coli; ii) quantify the protein by SDS PAGE and Bradford assay; iii) determine protein-DNA interaction of the purified protein by Electrophoretic Mobility Shift Assay. Bacterial culture prepared by inoculation of a single $E$. coli colony that had a GST fusion protein (gst: six-X10 hd) constructed by ligation of the six-7-hd (X10) sequence into the BamHI and EcoRI sites of the vector pGEX-2T, grown overnight, was sonicated using Cole-Palmer Ultrasonic Homogenizer. Fusion protein was eluted from the beads with Tris-glutathione buffer (50 mM Tris [pH 8.1], $20 \mathrm{mM}$ glutathione), which contained reduced Glutathione. SDS-PAGE was used to calculate the extracted bound protein. Total protein quantification was then estimated by the Bradford assay. Bovine Serum Albumin (BSA) absorbance values were used to plot the standard curve used to calculate the concentrations of the sample proteins. Nylon membrane was used for the electrophoretic transfer; membrane was cross linked and detected by Pierce's Chemiluminescent Nucleic Acid Detection module. Results showed that X10 gave a strong band shift observed in Lanes 6 and 7 for both 200 ng and 400 ng elute 1 samples; however, there was no shift in the bands for the wild-type, positive control. The concentration of the elute 1 was obtained by the Bradford assay as $242.52 \mathrm{ng} / \mu \mathrm{l}$ and that of elute 2 was $106.30 \mathrm{ng} / \mu \mathrm{l}$. Similarly, the result obtained by gel analysis was $300 \mathrm{ng} / \mu \mathrm{l}(0.3 \mu \mathrm{g} / \mu \mathrm{l})$ and 150 $\mathrm{ng} / \mu \mathrm{l}(0.15 \mu \mathrm{g} / \mu \mathrm{l})$ for elutes 1 and 2 respectively.

\section{Keywords}

Escherichia Coli, DNA-Protein Interaction, EMSA, Bradford Assay

\footnotetext{
${ }^{*}$ Corresponding author.

How to cite this paper: Ali, F.A. and Hamza, N.B. (2015) Study on Binding Affinity of a Glutathione S-Transferase (GST) Fusion Protein to DNA Probe. Advances in Bioscience and Biotechnology, 6, 345-352. 


\section{Introduction}

Electrophoretic Mobility Shift Assay (EMSA) or gel shift assay is one of the most powerful methods used to study the interaction of transcription factors to specific DNA sequences. Proteins recognizing specific DNA sequences play an important role in the regulation of gene expression and in DNA replication. The technique used is based on the fact that DNA-protein complexes move slower than unbound DNA in a native polyacrylamide gel [1].

Most of the eukaryotic genes transcribed by RNA Polymerase II contain the conserved TATA box which is present upstream of the transcription start site. The TATA-box binding protein is approximately $30 \mathrm{kDa}$. Component of the TFIID complex binds specifically to the heptanucleotide A and T residues and forms the core of the transcription initiation complex [2]. Many other specific transcription factors bind to the upstream promoter in a sequence specific manner and regulate gene expression, for example, a heat-shock transcription factor (HSTF) can bind to consensus heat-shock response elements and regulate expression of heat/stress inducible genes [2].

GST (Glutathione S-transferase) fusion protein (gst: six-X10 hd) is constructed by ligation of the six-7 (X10)hd sequence into the BamHI and EcoRI sites of the vector pGEX-2T, a commonly used expression vector (4948bp-long) [1]. The fusion is transformed into BL21(DE3)pLysS competent bacterial cells used for protein expression. The size of fusion protein (GST-Six7-HD-wildtype) is about $36 \mathrm{kDa}$. The GST fusion proteins were purified after overnight culture by Isopropylthiogalactoside (IPTG) induction and glutathione sepharose separation. IPTG induction uses Isopropylthiogalactoside which is added to induce T7 RNA polymerase.

Sodium dodecyl sulfate polyacrylamide gel electrophoresis (SDS-PAGE) is used to analyze and check the purity of the extracted bound protein. The SDS coating gives the protein a high net negative charge that is proportional to the length of the polypeptide chain. The molecular mass of a protein can be estimated by comparing the gel mobility of a band with those of protein standards.

Bradford protein assay involves binding of the dye Coomassie Brilliant Blue to protein in an acidic solution and once it is bounded then there is a simultaneous absorbance shift from $465 \mathrm{~nm}$ to $595 \mathrm{~nm}$. However, its bound condition is best detected at the maximal absorbance spectrum of $595 \mathrm{~nm}$. The increase in absorbance at this wavelength shows the increase in binding of protein-coomassie and that relationship is proportional, i.e. the higher the amino acid (or protein) content in a sample is, the higher the value of the optimal wavelength will be.

In Electrophoretic Mobility Shift Assay (EMSA), native non-denaturing gel electrophoresis is used to resolve protein: DNA complexes from free DNA. Non-denatured proteins are separated based on charge-to-mass ratio. Quantitative information about the site distribution, equilibria and kinetics of protein-DNA interactions can be acquired.

The capacity to determine protein: DNA complexes rely on stability of the complex during the brief time that it takes to migrate into the gel. Sequence specific interactions are stabilized by the use of comparatively low ionic strength electrophoresis buffer. Once it has entered the gel, the complex is stabilized by the caging effect of the gel matrix which causes dissociation of the complex; however, localized concentrations remain high, which promotes quick re-association. Therefore, even labile compounds can be determined by the Electrophoretic Mobility Shift Assay.

The importance of this study lies in the ability to resolve complexes or compounds which have different stoichiometry or conformation. Gel shift assays can also be used to identify sequence-specific DNA-binding proteins from unpurified sources such as in whole cell extracts, as well as be used in mutagenesis to identify the important binding sequences within a given gene's upstream regulatory region.

\section{Materials and Methods}

\subsection{Protein Purification}

Bacterial cell pellet expressing gst six 10x was carefully re-suspended in $3.5 \mathrm{ml}$ ice-cold PBST buffer (with protease inhibitors). Additional $3.5 \mathrm{ml}$ of cold, protease inhibitor-containing PBST was added (keeping the cells in ice). The cells were then sonicated using a Cole-Palmer ultrasonic homogenizer with a $2 \mathrm{~mm}$ needle for 10 seconds at $4{ }^{\circ} \mathrm{C}$ (an ear protection headset was worn); following sonication, $0.35 \mathrm{ml}$ of $20 \%$ triton X-100 was added and cell lysate was incubated for $30 \mathrm{~min}$ at room temperature $\left(20^{\circ} \mathrm{C}-25^{\circ} \mathrm{C}\right)$ with gentle shaking. After incubation, Cell lysate was centrifuged at $13,000 \mathrm{xg}$ for $10 \mathrm{mins}$ at $40^{\circ} \mathrm{C}$, the supernatant was transferred into fresh $15 \mathrm{ml}$ Falcon tube ( $50 \mu \mathrm{l}$ was saved for gel and Bradford). $0.25 \mathrm{ml}$ of PBS-equilibrated 50\% Glutathione Sepharose 4B 
slurry was added (to bind the protein) and left on a shaker for 30 - $40 \mathrm{~min}$ at room temperature, it was then centrifuged at $1500 \times \mathrm{rpm}$ to collect the matrix (i.e. slurry), supernatant was discarded and matrix was again re-suspended in $1 \mathrm{ml}$ PBST, it was gentle tapped and the suspension was transferred to a $1.5 \mathrm{ml}$ Eppendorf tube and again centrifuged at $1500 \mathrm{rpm}$ for $1 \mathrm{~min}$, this was repeated 4 times. After the last wash, supernatant was removed (as much as possible but without touching the matrix) and the matrix was re-suspended in $300 \mu \mathrm{l}$ of elution buffer (10 mM reduced glutathione), it was then left on shaker for $10 \mathrm{~min}$ at room temperature, centrifuged at $2000 \mathrm{rpm}$ for $1 \mathrm{~min}$ at room temperature, supernatant was saved as elute 1. Again $300 \mu \mathrm{l}$ of elution buffer was added to the matrix, the mixture was left on a shaker for $10 \mathrm{~min}$ at room temperature, then centrifuged at 2000 $\mathrm{rpm}$ for $1 \mathrm{~min}$ and supernatant was saved as elute 2, both elutes 1 and 2, were kept at $4^{\circ} \mathrm{C}$ in the fridge.

\subsection{Sodium Dodecyl Sulfate Polyacrylamide Gel Electrophoresis (SDS-PAGE)}

SDS PAGE gel was prepared using 12\% SDS running gel and 5\% stacking gel. A 10 well-comb was used. The samples to be loaded $10 \mu 1$ of each of the cell lysate, elute 1, elute 2, oval albumin were all prepared in separate $1.5 \mathrm{ml}$ Eppendorf tubes, $2 \mu \mathrm{l}$ of 5x SDS-PAGE sample was added in each tube and all the sample in each tube $(12 \mu \mathrm{l})$ was loaded on separate wells in the gel. $5 \mu \mathrm{l}$ of diluted low Range Molecular weight Marker from BioRad was also loaded in one lane as Marker.

The gel was then run at $100 \mathrm{~V}$ for $15 \mathrm{~min}$ and then at $200 \mathrm{~V}$ for 1.5 hours. The gel was then stained with Coommassie gel-staining solution for 3 hours and destained for overnight. This was followed by gel analysis.

\subsection{Determination of Protein Concentration}

The protein concentration was measured using the Bradford assay. A BSA standard curve was made and the samples were prepared as shown in Table 1 .

$1 \mathrm{ml}$ of Bradford reagent was added to each cuvette and the reaction mixture was carefully stirred. The absorbance was measured at $595 \mathrm{~nm}$ against a blank, $200 \mu 10.12 \mathrm{M} \mathrm{NaCl}$ solution with $1 \mathrm{ml}$ Bradford reagent. The values obtained were used to plot the standard curve.

\subsection{Electrophoretic Mobility Shift Assay (EMSA)}

\subsubsection{Gel Preparation and Pre-Run}

\section{1) Unit set up}

The glass plates were well washed with water and soap; and rinsed with MilliQ water and then wiped with 70\% ethanol. The plates were mounted and some water was poured into the assembled unit so as to remove any residual ethanol and to ensure there was no leakage prior to gel casting. The water was drained by tilting the unit and water drops was wiped with tissue paper.

\section{2) Gel casting (6\% non-denaturing, native PAGE)}

The following were added into a $15 \mathrm{ml}$ Falcon tube; $1.5 \mathrm{ml}$ acrylamide mix (containing $30 \%$ acrylamide and $2 \%$

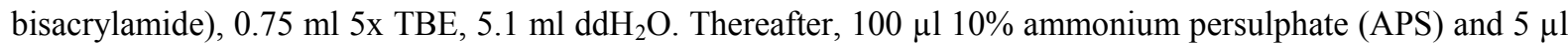
TEMED were added last. The gel mix was poured into the assembled unit using a pipette. The gel mix was filled to the top and a 10 -well comb was inserted carefully and gradually from one side avoiding trapping air bubbles beneath the comb. The gel was allowed to polymerize for $40 \mathrm{~min}$. After polymerization, it was disconnected and carefully wrapped in a plastic sheet including wet tissue papers and stored overnight in the fridge at $4^{\circ} \mathrm{C}$.

\section{3) Pre-run}

The gel was assembled in the electrophoresis unit and filled with $0.5 \mathrm{x}$ TBE. The gel was pre-run for 1 hour at $200 \mathrm{~V}$. According to the script, each well should be flushed twice with $0.5 \mathrm{x}$ TBE before loading the sample, in order to remove residuals APS or salts but that was done.

\subsubsection{Binding Reaction and Electrophoresis}

The samples to be loaded were prepared as shown in Table 2 .

The binding reaction was incubated for $20 \mathrm{~min}$ at room temperature (around $20^{\circ} \mathrm{C}-25^{\circ} \mathrm{C}$ ), then $5 \mu 1$ of $5 \mathrm{x}$ EMSA buffer was added to each of the $20 \mu \mathrm{l}$ binding reaction. The mixture was pipetted up and down 2 - 3 times so as to allow the reaction to mix; $18 \mu \mathrm{l}$ of the sample was loaded on the pre-running gel. It gel was left to 
Table 1. Sample preparation for determination of protein concentration.

\begin{tabular}{rcccccc}
\hline & 1 & 2 & 3 & 4 & 5 & 6 \\
\cline { 2 - 6 } & Blank & Blank & S1 & S3 & S3 & S4 \\
\hline $0.12 \mathrm{M} \mathrm{NaCl}(\mu 1)$ & 200 & 200 & 190 & 175 & 150 & 125 \\
$0.2 \mathrm{mg} / \mathrm{ml} \mathrm{BSA}(\mu \mathrm{l})$ & & & 10 & 25 & 50 & 75 \\
\hline
\end{tabular}

Table 2. Sample preparation scheme for native non-denaturing gel electrophoresis*

\begin{tabular}{|c|c|c|c|c|c|c|c|c|c|}
\hline Component & Final amount & Lane 1 & Lane 2 & Lane 3 & Lane 4 & Lane 5 & Lane 6 & Lane 7 & Lane 8 \\
\hline $4 \mathrm{x}$ binding buffer & $1 \times$ & $5 \mu 1$ & $5 \mu 1$ & $5 \mu 1$ & $5 \mu 1$ & $5 \mu 1$ & $5 \mu 1$ & $5 \mu 1$ & $5 \mu 1$ \\
\hline Poly dIdC $925 \mathrm{ng} / \mu \mathrm{l}$ & $50 \mathrm{ng}$ & $2 \mu 1$ & $2 \mu 1$ & $2 \mu 1$ & $2 \mu 1$ & $2 \mu 1$ & $2 \mu 1$ & $2 \mu 1$ & $2 \mu 1$ \\
\hline Protein & 200 & - & $\mathrm{w}$ & $\mathrm{x}$ & $\mathrm{x}$ & $2 \mathrm{x}$ & $\mathrm{y}$ & $2 y$ & $2 z$ \\
\hline $\begin{array}{l}\text { Labeled DNA } \\
\qquad(5 \mathrm{nM})\end{array}$ & $10 \mathrm{fmol}$ & $2 \mu 1$ & $2 \mu 1$ & $2 \mu 1$ & $2 \mu 1$ & $2 \mu 1$ & $2 \mu 1$ & $2 \mu 1$ & $2 \mu 1$ \\
\hline $\begin{array}{l}\text { Unlabelled DNA } \\
\qquad(500 \mathrm{nM})\end{array}$ & $2 \mathrm{pmol}$ & - & - & 4 & - & - & - & - & - \\
\hline MilliQ water & & $11 \mu 1$ & $10 \mu 1$ & $10 \mu 1$ & $10 \mu 1$ & $9 \mu 1$ & $10 \mu 1$ & $9 \mu 1$ & $9 \mu 1$ \\
\hline Total & & $20 \mu 1$ & $20 \mu 1$ & $20 \mu 1$ & $20 \mu 1$ & $20 \mu 1$ & $20 \mu 1$ & $20 \mu 1$ & $20 \mu 1$ \\
\hline
\end{tabular}

*Lane 1, Free probe (without protein); Lane 2, Negative control I (GST); Lane 3, Wild-type protein (competitor); Lane 4, Wild type protein (positive control); Lane 5, Wild type protein (positive control); Lane 6, Sample: Elution 2 (200 ng = $1 \mu 1$ ); Lane 7, Sample: Elution 2 (400 ng = $2 \mu 1$ ); Lane 8, Mutant protein (negative control).

stand for 15 min to avoid smiling, and the gel was then run at $80 \mathrm{~V}$. It was stopped when the bromophenol blue dye has migrated approximately $2 / 3$ to $3 / 4$ down the length of the gel for $50 \mathrm{~min}$.

\subsubsection{Electrophoretic Transfer and Cross-Linking}

Nylon membrane was soaked in $0.5 \times$ TBE for 20 mins and the gel was carefully removed and transferred onto the nylon membrane, where it was sandwiched in a clean electrophoretic transfer unit and the following: from the cathode (black), sponge, 3 filter papers (Whatman nr.3), the gel and towards the positive charged nylon membrane, 2 fliter papers and a sponge. After the transfer, the membrane was placed with the bromophenol blue side up on a dry paper towel. Transferred DNA (and protein) was cross-linked to the nylon membrane for 15 mins with the membrane face down on a transilluminator equipped with 312-nm bulbs.

\subsubsection{Detection}

The blocking buffer and the $4 \mathrm{x}$ wash buffer were gently warm in a water bath to $37^{\circ} \mathrm{C}-50^{\circ} \mathrm{C}$, until all particles were dissolved. $20 \mu \mathrm{l}$ blocking buffer was added to block the membrane and was incubated for 15 min with gentle shaking. $40 \mu \mathrm{l}$ of stabilized streptavidin-horseradish peroxide conjugate was added to with the blocking buffer (approx. 1:500 dilutions), it was incubated for 15 min with gentle shaking. 1x wash solution was prepared by adding $25 \mathrm{ml}$ of $4 \mathrm{x}$ wash buffer to $75 \mathrm{ml}$ MilliQ water. It was rinsed briefly with $30 \mathrm{ml}$ of $1 \mathrm{x}$ wash solution. The membrane was washed 3 times for 10 min each wash was $1 \mathrm{x}$ wash solution with gentle shaking.

The substrate working solution was prepared by adding $2.5 \mathrm{ml}$ luminol enhancer solution to $2.5 \mathrm{ml}$ stable peroxide solution, and was kept inside the drawer. The membrane was removed from the substrate equilibration buffer, the edge was carefully blotted to remove excess buffer and the substrate working solution was poured completely covering the surface. It was then incubated for $5 \mathrm{~min}$ with gentle tilting back and forth. After incubation, the membrane was removed from the working solution, the edge was again blotted using tissue papers to remove excess buffer and wrapped in a plastic paper avoiding bubbles and wrinkles. It was then placed in a film cassette and an X-ray film was put using Amersham's Hyperfilm ECL, which was optimized for chemoluminescence detection. The film was developed, exposure time was adjusted to obtain the desired signal and the bands were analyzed. 


\section{Results}

\subsection{Gel Analysis}

In Figure 1, the arrows show the bands of the samples, elute 1 (black) and 2 (green). The bands correspond to approximately $35 \mathrm{kDa}$ band size of the Marker Protein Ladder (250 ng). The oval albumin band that corresponds to the protein band is shown by the red arrow below, the band is rather faint.

Oval albumin was used as standard protein. The amount of oval albumin protein loaded was $10 \mu \mathrm{l}$ each microlitre is $50 \mathrm{ng}$, this implies the total amount of oval albumin loaded was $500 \mathrm{ng}$.

The strength of the band of Elute 1 is 6 times the corresponding band of the standard protein (oval albumin). This is multiplied by the total amount of oval albumin, which will equate to $(500 * 6), 3000 \mathrm{ng}$.

However, the amount of the sample protein loaded was $10 \mu$, so the amount of protein in the sample will be equal to $3000 / 10=300 \mathrm{ng} / \mu \mathrm{l}$ an equivalent of $0.3 \mu \mathrm{g} / \mu \mathrm{l}$.

Similarly, the strength of the band for elute 2 is 3 times the corresponding band of the oval albumin, therefore $(500 * 3), 1500 \mathrm{ng}$. The amount of elute 2 loaded is $10 \mu \mathrm{l} ; 1500 / 10=150 \mathrm{ng} / \mu \mathrm{l}$ an equivalent of $0.15 \mu \mathrm{g} / \mu \mathrm{l}$.

\subsection{Determination of Protein Concentration by Bradford Assay}

The absorbance of the samples i.e. elutes 1 and 2, and the clear lysate are all shown in Table 3. The concentrations of the samples were calculated from the absorbance measured at $595 \mathrm{~nm}$ and deduced from the equation of the standard curve of BSA protein Figure 2. The concentration of the samples were determine by substituting for the values of $y$ in the linear regression equation worked out from the standard curve, with the values of the absorbance of the sample and calculating for the value of $\mathrm{x}$, which represents the concentrations.

The concentration of the elute 1 is obtained as $242.52 \mathrm{ng} / \mu 1$ and that of elute 2 is $106.30 \mathrm{ng} / \mu 1$.

\subsection{Electrophoretic Mobility Shift Assay (EMSA)}

The results gave a strong band shift in Lanes 6 and 7 which are the lanes for the sample protein E1 both for 200 ng and $400 \mathrm{ng}$. Both Lanes had equal amount of labeled DNA $5 \mathrm{nM}(2 \mu \mathrm{l})$ (Figure 3). There are no other shifts shown in the figure for all other proteins both for the negative and positive control. The red arrow points to the

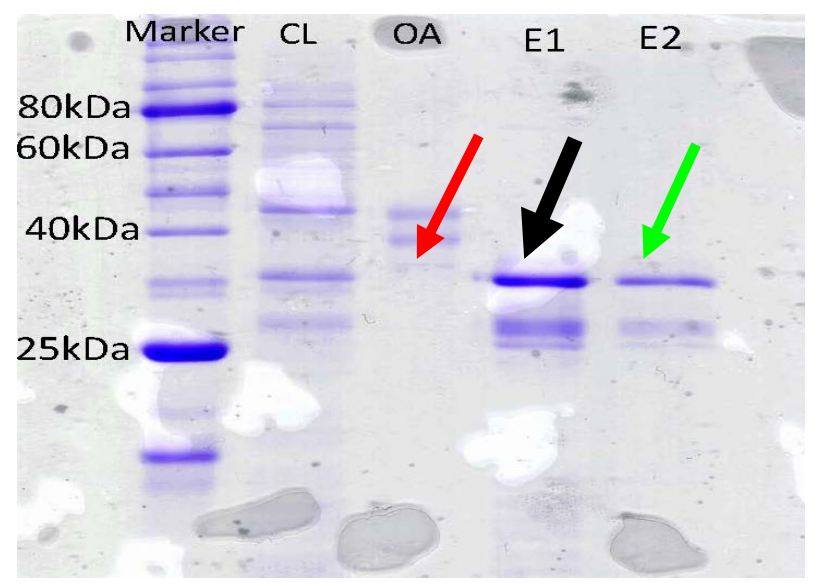

Figure 1. SDS-PAGE of Glutathione S-transfarase (GST) fusion proteins purified by IPTG induction technique from BL21 (DE3) pLysS bacterial cells transformed with pGEX-2T expressing gst: six 7 hd-X10. The polypeptide was visualized by commassie gel stain. Marker is the protein ladder (250ng), Lane marked CL-clear lysate, Lane marked OA-oval albumin, Lanes marked E1 \& E2-elute1 and elute 2 respectively. The black arrow shows the band of the Elution 2 sample and the red arrow shows the band of Elution 1. Both bands correspond to approximately $35 \mathrm{kDa}$ as compared to the band on the Marker. 


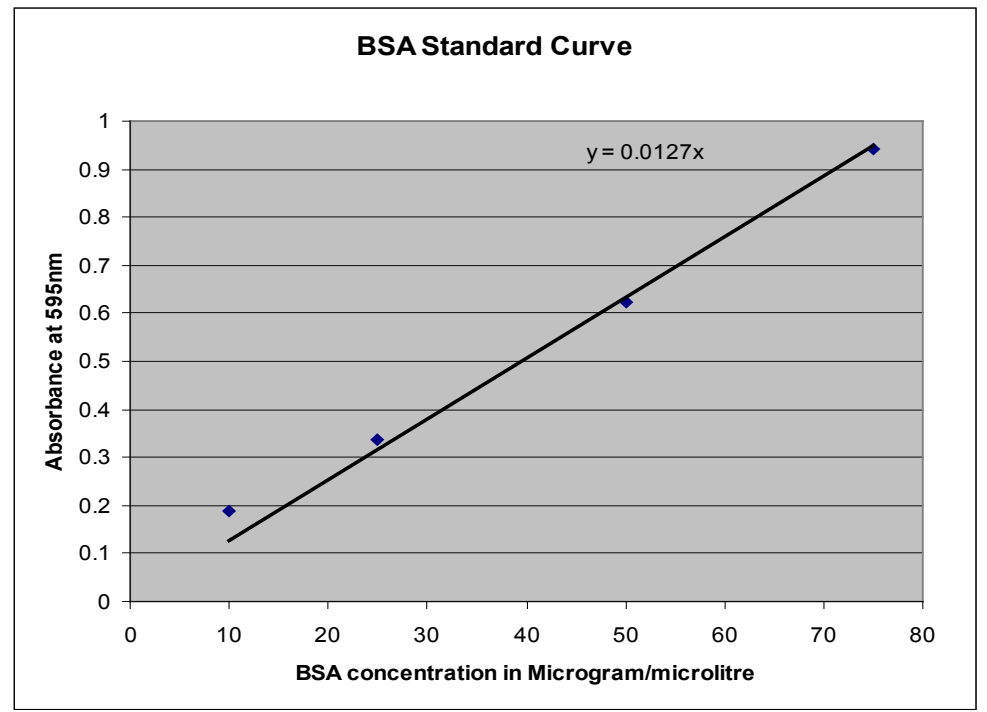

Figure 2. BSA Standard Curve with absorbance measured at $595 \mathrm{~nm}$, a linear regression was deduced with equation of $y=0.0127 x$.

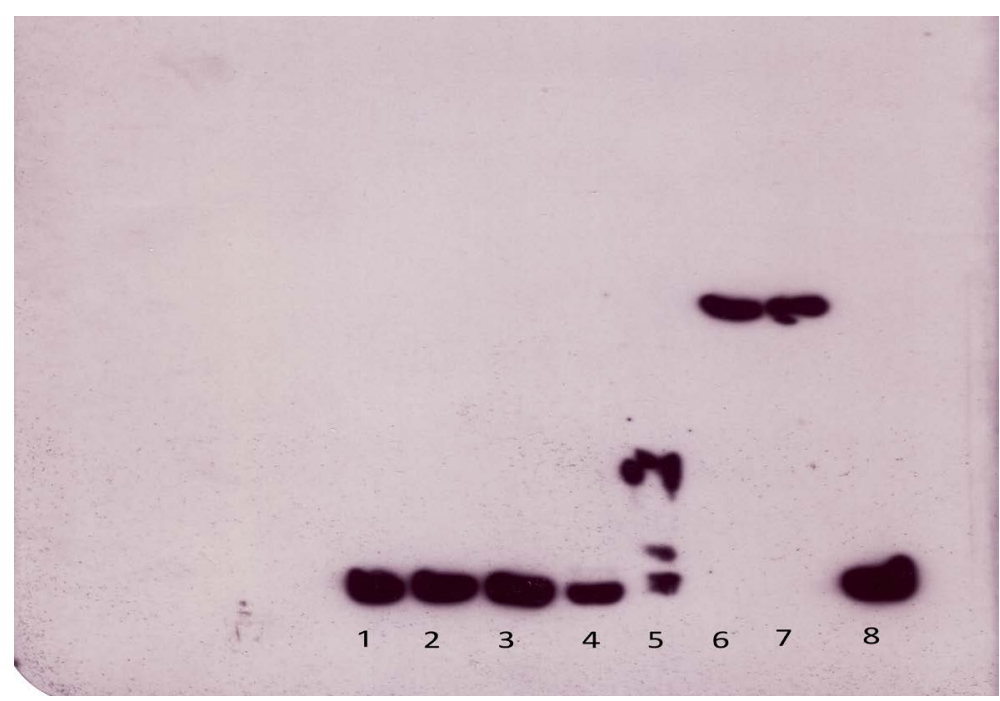

Figure 3. Electrophoretic Mobility Shift Assay (EMSA) results performed in the presence of $10 \mathrm{mM}$ reduced glutathione eluted GST fusion proteins (gst: six-X10hd) including other proteins, subjected to non-denaturing polyacrylamide gel electrophoresis and detected by Pierce's Chemiluminescent Nucleic Acid Detection Mod-ule . . Lane 1: Free probe; Lane 2: GST (negative control 1); Lane 3: Wild-type protein with excess of unlabelled DNA (competition); Lane 4: Wild-type protein (positive control1); Lane 5: Wild-type protein (positive control 2); Lane 6: Sample E1 (200 ng); Lane 7: Sample E1 (400 ng); Lane 8: Mutant protein (negative control 2).

bands with retarded mobility due to DNA-protein binding. The black arrow shows an incomplete shift perhaps due to little protein samples or contaminations.

\section{Discussion \& Conclusions}

\subsection{Gel Analysis}

The gel analysis results were good. Although the proteins in elutes 1 and 2 seemed not to be very well purified, 
Table 3. Absorbance values used in the BRADFORD assay \& sample concentration values determined from the standard BSA curve *

\begin{tabular}{|c|c|c|c|c|c|c|c|c|}
\hline \multicolumn{4}{|c|}{ Standards } & \multicolumn{5}{|c|}{ Samples } \\
\hline \multicolumn{2}{|c|}{$0.2 \mathrm{mg} / \mathrm{ml} \mathrm{BSA}$} & \multirow{2}{*}{$\mathrm{A}_{595 \mathrm{~nm}}$} & \multirow{2}{*}{ Sample } & \multirow{2}{*}{ Probe } & \multirow{2}{*}{ Dilution } & \multirow{2}{*}{$\mathrm{A}_{595 \mathrm{~nm}}$} & \multirow{2}{*}{$\begin{array}{l}\text { Conc. } \\
{[\mathrm{ng} / \mu \mathrm{l}]}\end{array}$} & \multirow{2}{*}{$\begin{array}{c}\text { Final Conc. } \\
{[\mathrm{ng} / \mu \mathrm{l}]}\end{array}$} \\
\hline Sample & {$[\mathrm{ng} / \mu \mathrm{l}]$} & & & & & & & \\
\hline S1 & 10 & 0.187 & S5 & Elute 1 & $1: 10$ & 0.308 & 24.252 & 242.52 \\
\hline S2 & 25 & 0.336 & S6 & Elute 1 & $1: 4$ & 0.327 & 25.748 & 109.99 \\
\hline S3 & 50 & 0.623 & S7 & Elute 2 & $1: 10$ & 0.135 & 10.630 & 106.30 \\
\hline \multirow[t]{3}{*}{ S4 } & 75 & 0.941 & S8 & Elute 2 & $1: 4$ & 0.125 & 9.843 & 39.37 \\
\hline & & & S9 & Clear Lysate & $1: 40$ & 0.187 & 14.724 & 588.98 \\
\hline & & & S10 & Clear Lysate & $1: 20$ & 0.257 & 20.236 & 404.74 \\
\hline
\end{tabular}

${ }^{*}$ The absorption and concentration values for both the standard and protein sample. The standard curve was drawn from the Absorbance and concentration values of the Standard protein (BSA) values indicated in the table above.

they showed good verified bands. The bands of the sample proteins clearly corresponded to the bands of both the marker and standard protein. This made determination of the protein concentration in those samples easier. The clear lysate shows so many bands, an indication of impurities in the sample. The bands of the samples elutes 1 and 2 indicate that both proteins are of the same molecular weight. It corresponds to approximately $35 \mathrm{kDa}$ band of the marker protein. The band of the oval albumin that corresponds directly to the band of the sample protein is very faint. Perhaps the amount or the concentration of the oval albumin loaded was too little. It is also clear that the molecular weight of the oval albumin is much higher than the sample protein as observed from the gel.

The amount of protein calculated in elute 1 is $242.52 \mathrm{ng} / \mu \mathrm{l}$ and that of elute 2 is $106.30 \mathrm{ng} / \mu \mathrm{l}$. The calculation based on comparison of gel band to that of the marker or standard curve is rather subjective and depends on personal opinion which sometimes may not be correct. So, the results may be considered as a rough estimation of the protein concentration.

\subsection{Bradford Assay}

The results obtained from the protein determination by Bradford assay are good and are based on absorbance obtained from the standard curve. The samples of elute 1 were taken in two dilutions: one with a dilution of 1:10 and the other with dilution of 1:4, with approximately the same absorbance of 0.308 and 0.327 respectively, i.e. 1.3. Similarly, elute 2 was taken in two dilutions: one with a dilution of 1:10 and the other with dilution of 1:4; the absorbance was 0.135 and 0.125 respectively, i.e. 0.1 . The clear lysate showed different absorbance; the dilutions taken were higher, but the protein was less purified and therefore showed less concentration. The two were taken in a dilution of 1:40 and 1:20. They gave an absorbance of 0.187 and 0.257 respectively, i.e. approximately 0.2 and 0.3 . Although the two samples gave different dilutions absorbance, the absorbance was within the range of the other two purified sample proteins.

Elute 1 has the highest concentration, meaning that the amount of purified protein is higher in elute 1 and it is the sample used in Electrophoretic Mobility Shift Assay.

In conclusion, the results obtained using the Bradford assay didn't have much difference with that of the gel analysis. The two samples elute 1 and 2 gave an approximately the same concentration, e.g. elute 1 had a concentration of $300 \mathrm{ng} / \mu \mathrm{l}$ and in the Bradford assay gave a concentration of $242.52 \mathrm{ng} / \mu \mathrm{l}$.

\subsection{Electrophoretic Mobility Shift Assay (EMSA)}

Eight samples were loaded on the gel. The sample loaded in Lane 1 was a free probe and didn't contain any protein sample; it only contained some labelled DNA and binding buffer didn't show any shift. Sample in Lane 2 is GST; GST is used here as a negative control, which is the tool or tag for the protein purification and not the protein itself. The samples loaded in Lanes 1 and 2 are both to exclude the fact that it is the labeled DNA or the 
GST that causes the shift, to check whether the DNA-binding activity is due to the presence of these samples; so, both are negative control and don't show a shift.

Lane 3 was loaded with wild-type protein, but with excess unlabelled DNA. There were two types of DNA: one labeled used in the assay and the unlabeled because there was a competition on the active site on which the proteins should bind. And because the unlabelled DNA was in excess, there was a higher probability that many of the proteins bound to the unlabelled protein and a little or none bound to the labeled DNA, therefore resulting in no shift.

Lanes 4 and 5 are loaded with the same wild-type parental protein, but with different concentrations. Lane 4 has less concentration than Lane 5, but both are supposed to be positive control. However, during the experiment, the sample provided was too little and there was apparently no sample of wild-type protein added in these lanes. The amount to be added was few, i.e. $1 \mu \mathrm{l}$ and $2 \mu \mathrm{l}$ respectively and the bottom of the tube which had the sample couldn't clearly show whether there was a sample in it or not. Since the sample was taken with $10 \mu 1$ micropipette, it was not clear whether there was a sample on the tip or not. This was clearly evident in the 5th lane which showed that there were few wild-type proteins with some contaminations or impurities, so there was no clear shift. However, both were supposed to be positive control. If these proteins were purified and were the samples used in the study, such problems could have been overcome by addition of a non-ionic detergent (as $0.1 \%$ Triton X-100 or $2 \% \mathrm{~N}$-octyl glucoside) to reduce non-specific hydrophobic interactions that might prevent solubilization or elution of the fusion protein.

Lanes 7 and 8 were loaded with samples from elute 1 with different concentrations. Both samples showed strong band shift verifying its typical DNA-binding activity and also suggesting that the polypeptide comprising protein X10 had intrinsic DNA-binding activity.

Lane 8 was loaded with a Z14 a nonsense-mutated protein (L34X mutation), used as a negative mutation. It didn't show a shift because it was a nonsense mutated protein. A nonsense mutation is a point mutation that results in a premature stop codon or nonsense codon in a transcribed mRNA. There are three stop codons, UAA, UAG and UGA, and therefore when a nonsense mutation converts a transcribed codon, e.g. TAA, TAG, or TGA, to any of the three depending on the position of the nucleotide above, it will result in a premature abandoning of the gene expression and hence be nonfunctional. This is particularly evident when such mutations occur earlier in the gene.

Although the X10 is also mutated, it has a mis-sense mutation which is a point mutation where a single nucleotide changes to cause substitution of different amino acid. It can result in either a transition or transversion mutation. In this case, X10 has G46S mutation, in which the amino acid glycine has been replaced with serine at 46 position of the protein. However, according to the literature homeodomain, containing transcription factor six7 is a highly specific DNA-binding sequences, shown in the script. The mutation doesn't seem to be at the sequence where the actual binding takes place. DNA-binding proteins may have one or more subdomains: one containing a conserve motif that contacts the DNA directly and another less well conserved that may modulate either the conformation or accessibility of the binding domain.

\section{Acknowledgements}

The authors wish to pass words of gratefulness and appreciations to Prof. H. C. Seo from the University of Bergen. Gratitude is also extended to Marrianne Brattas and Emilia Lohndal and Grether for their valuable assistance.

\section{References}

[1] Garner, M.M. and Revizn, A. (1981) A Gel Electrophoresis Method for Quantifying the Binding of Proteins to Specific DNA Regions: Application to Components of Escherichia coli Lactose Operon Regulatory System. Nucleic Acids Research, 9, 3047-3060. http://dx.doi.org/10.1093/nar/9.13.3047

[2] Guarente, L. and Bermingham-McDonogh, O. (1992) Conservation and Evolution of Transcriptional Mechanisms in Eukaryotes. Trends in Genetics, 8, 27-32. http://dx.doi.org/10.1016/0168-9525(92)90021-U 